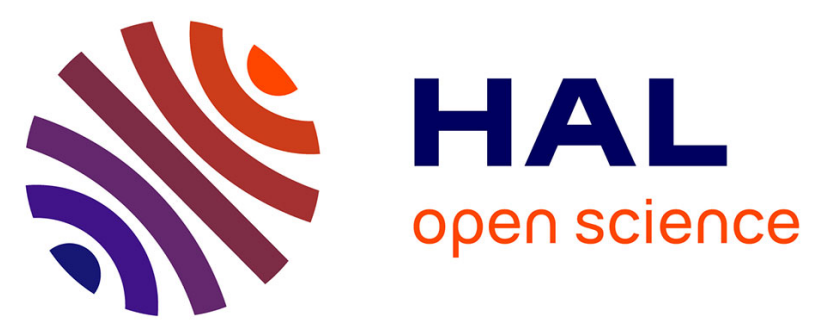

\title{
A Novel Proteomics-Based Strategy for the Investigation of Peptide Sequences in Extraterrestrial Samples
} Justin Lange, Fabiola Djago, Balkis Eddhif, Quentin Remaury, Alexander Ruf, Nathalie Karpel Vel Leitner, Louis Hendecourt, Grégoire Danger, Claude Rodier, Sébastien Papot, et al.

\section{To cite this version:}

Justin Lange, Fabiola Djago, Balkis Eddhif, Quentin Remaury, Alexander Ruf, et al.. A Novel Proteomics-Based Strategy for the Investigation of Peptide Sequences in Extraterrestrial Samples. Journal of Proteome Research, 2020, 20 (2), pp.1444-1450. 10.1021/acs.jproteome.0c00700 . hal03052767

\section{HAL Id: hal-03052767 https://hal.science/hal-03052767}

Submitted on 18 Nov 2021

HAL is a multi-disciplinary open access archive for the deposit and dissemination of scientific research documents, whether they are published or not. The documents may come from teaching and research institutions in France or abroad, or from public or private research centers.
L'archive ouverte pluridisciplinaire $\mathbf{H A L}$, est destinée au dépôt et à la diffusion de documents scientifiques de niveau recherche, publiés ou non, émanant des établissements d'enseignement et de recherche français ou étrangers, des laboratoires publics ou privés. 


\title{
A novel proteomics-based strategy for the investigation of peptide se- quences in extraterrestrial samples
}

\author{
Justin Lange, Fabiola Djago, Balkis Eddhif, Quentin Blancart Remaury, Alexander Ruf, Nathalie Karpel \\ Vel Leitner, Louis Le Sergeant d'Hendecourt, Grégoire Danger, Claude Geffroy Rodier, Sébastien Pa- \\ pot, and Pauline Poinot*
}

Justin Lange, Fabiola Djago, Balkis Eddhif, Quentin Blancart Remaury, Nathalie Karpel Vel Leitner, Claude Geffroy Rodier, and Pauline Poinot - University of Poitiers, UMR CNRS 7285, Institut de Chimie des Milieux et Matériaux de Poitiers (IC2MP), E.BiCoM Team, 4 rue Michel-Brunet, TSA 51106, 86073 Poitiers cedex 9, France.

Alexander Ruf, Louis Le Sergeant d'Hendecourt, Grégoire Danger - Aix-Marseille University, UMR CNRS 7345, Physics of Ionic and Molecular Interactions (PIIM), ASTRO Team, Avenue Escadrille Normandie-Niémen, 13397 Marseille cedex 20 , France.

Grégoire Danger - Institut Universitaire de France (IUF), Marseille, France

Sébastien Papot - University of Poitiers, UMR CNRS 7285, Institut de Chimie des Milieux et Matériaux de Poitiers (IC2MP), Groupe « Systèmes Moléculaires Programmés », rue Michel-Brunet, TSA 51106, 86073 Poitiers cedex 9, France.

\begin{abstract}
Method development is part of the objectives of astrophysical community for characterizing the organic matter in objects of the Solar System. In this context, we report on the development of an enzyme-catalyzed stereoselective hydrolysis, inspired from the proteomics discipline, which has enabled the indirect detection of peptide sequences in extraterrestrial samples. A proof of concept has been performed on a Murchison extract. We showed that our approach can successfully highlight L- and D-amino acids involved in peptide bonds. While we showed that some D-amino acids must have been involved in peptide bonds, we cannot at this stage conclude on the indigenous or exogenous nature of these biopolymers. However, our strategy constitutes the first step towards the direct UPLC-MS evidence of peptide sequences in extraterrestrial samples. It should thus participate to deepen knowledge on the molecules available in the Solar System, hence providing new clues on their chemical history, especially on Earth.
\end{abstract}

Many organic molecules present in comets or asteroids may have been delivered to the Earth during the early phases of the planet formation all along the first hundred million years of the Solar System ${ }^{1}$. Molecular identification has become a key challenge in astrobiology in order to understand their potential role in the emergence of life ${ }^{2,3}$. Within this framework, numerous building blocks of living systems such as amino acids, sugars and nucleobases have been highlighted in various extraterrestrial environments ${ }^{4-8}$. In contrast, the direct or indirect detection of macromolecules such as peptides, that would represent a major advance for understanding the origin of organized molecular systems on the early Earth, remains challenging.

Until now, gas chromatography coupled to mass spectrometry (GC-MS) represents the technique of choice for amino acids and other water-soluble compounds analysis in extraterrestrial objects ${ }^{9}$. For allowing the detection of these molecules, samples have to undergo several chemical pre-treatments, typically consisting in an acid hydrolysis (usually with hydrochloric acid, $\mathrm{HCl}$ ) followed by a derivatization reaction to enhance compounds volatility or detectability $5,10,11$. However, such processes impose rather harsh conditions which are likely to degrade organic compounds (fragmentation reactions, oxidation, rearrangements, racemization), hence giving incomplete information on the structure of the molecules present in the native sample. Therefore, the presence of peptide sequences in such extraterrestrial samples cannot be deduced from this analytical procedure.

Here, we present a new strategy designed to highlight, without ambiguity, amino acids involved in peptide bonds within extraterrestrial samples. For this purpose, we transferred a proteomics approach based on the use of aminopeptidase M (APM, EC 3.4.11.2 ${ }^{12,13}$ ) which catalyzes stereoselectively the stepwise removal of L- $\alpha$-amino acids from the $N$-terminal end of peptides ${ }^{14,15}$. APM stereoselectivity has already been used with success to differentiate neuropeptides containing D-amino acids from those including only L-residues in tissue extracts ${ }^{15-18}$. Very recently, an APM-based protocol has also enabled to indicate $\mathrm{L}$ to $\mathrm{D}$-amino acids isomerization in peptides of the central nervous system in animals ${ }^{19}$. In this work, we propose a variation of this approach with the aim to search for peptide sequences in meteorites. In contrast to $\mathrm{HCl}$ hydrolysis which induces the release of amino acids from a wide variety of precursors, peptide sequences can be probed through the generation of free L-amino acids as the result of the stereoselective enzymecatalyzed cleavage of peptide bonds (Figure 1).

After optimization of the standard enzymatic conditions (enzyme/peptides ratio, $\mathrm{pH}$ and temperature, Figure S1), we 
checked the selectivity of APM for $\mathrm{N}$-terminal L-homochiral peptide bonds in comparison to the standard $\mathrm{HCl}$ hydrolysis protocol. For that purpose, we evaluated the hydrolysis rate of L-homochiral peptides and other potential amino acid precursors, such as esters and diketopiperazines already reported in meteorite extracts ${ }^{7,8}$.

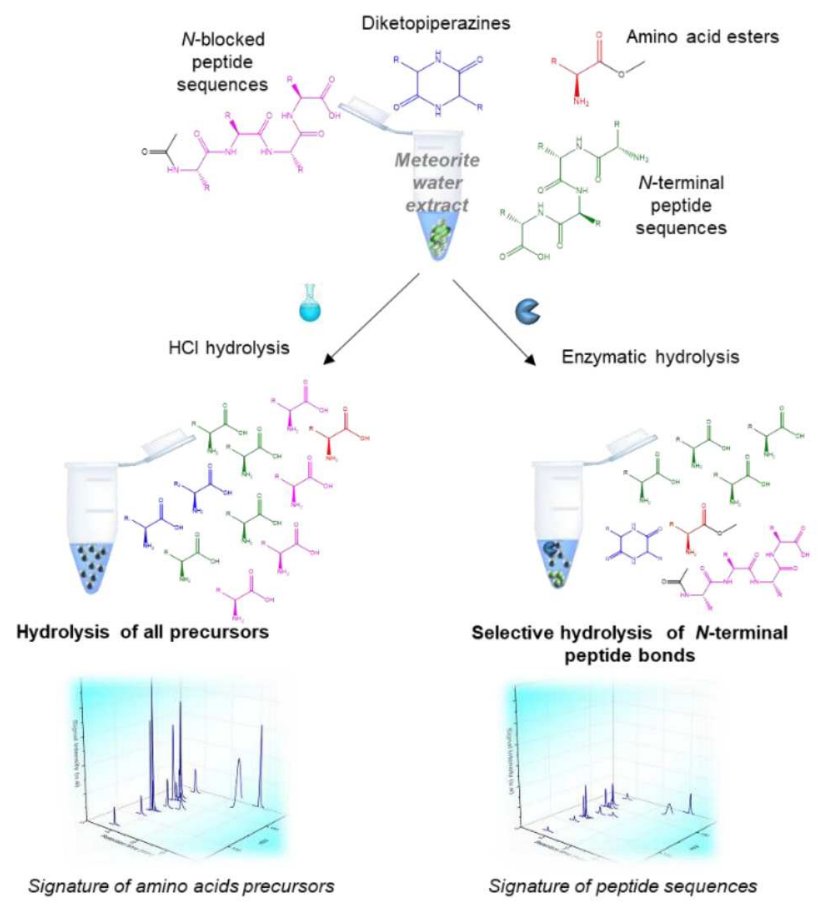

Figure 1. Enzymatic versus chemical strategy to highlight peptide sequences in meteorite water extract.

Thus, various amino acid precursors were incubated in phosphate buffers ( $\mathrm{pH}$ 6.9) for $4 \mathrm{~h}$ at $30^{\circ} \mathrm{C}$ with or without APM and the mixtures were analyzed by UPLC-HRMS (Table S2, Figures S2-S3). In parallel, standard solutions were also submitted to the standard $6 \mathrm{M} \mathrm{HCl}$ hydrolysis for $24 \mathrm{~h}$. In the absence of the exopeptidase, partial hydrolysis was recorded with the whole tested molecules including peptides of various lengths, the protected peptide Ac-Ala-Ala-Ala-OMe, the piperazine-2,5-dione and the phenylglycine methyl ester (Table S2). This partial hydrolysis was attributed to the presence of formic acid added in the mixture after $4 \mathrm{~h}$ of incubation to be consistent with the conditions employed in enzymatic experiments. When incubated with APM for $4 \mathrm{~h}$, unprotected peptides were almost totally consumed as the result of the enzyme-catalyzed peptide bonds cleavage (Table S2, entries 1-5).

This result was confirmed by the appearance of significantly higher quantities of free amino acids compared to the experiment in which peptides were not submitted to enzymatic hydrolysis (Figure S4). In contrast, such an increase hydrolysis rate was not observed with the other amino acid precursors when incubated with APM (Table S2, entries 6-8). On the other hand, all the compounds were hydrolyzed after $\mathrm{HCl}$ treatment (Table S2, entries 1-8, Figures S2-S3). Surprisingly, the octapeptide (Table S2, entry 5) was not totally hydrolyzed either with APM or $\mathrm{HCl}$. This result can be explained by the folding of such a hydrophobic peptide in water which reduces the accessibility of peptide bonds to either chemical reagents or enzymes.

This benchmark experiment has thus confirmed the selectivity of APM for hydrolysis of $\mathrm{N}$-terminal L-homochiral peptide bonds while the non-selective acid hydrolysis can generate free amino acids from a wide variety of precursors. Furthermore, these results indicated that APM could be useful to highlight selectively amino acids bound in the form of peptides in extraterrestrial objects. Indeed, if peptide sequences are present, samples submitted to APM digestion should produce higher amounts of free amino acids than when treated under neutral hydrolysis conditions (Figure S4).

In order to investigate this hypothesis, we applied the proteomics-based strategy to detect peptide bonds in a meteoritic extract. We decided to work on the Murchison meteorite, considered as the reference for meteorites rich in organic compounds ${ }^{5,8}$. This meteorite has indeed revealed a wide variety of molecular building blocks of life, including several amino acids found in the proteins of living organisms and one dipeptide, glycylglycine, which remains the sole dipeptide identified with confidence so far ${ }^{21}$. Increases of amino acids amounts detected when Murchison samples were submitted to strong acid hydrolysis 10,21-24 supported the presence of acid-labile precursors with amide or ester bonds, as well as complex peptide like structures ${ }^{25}$. However, the lack of selectivity of these acidic conditions did not allow concluding on the presence of peptides in the meteorite.

We thus analyzed the sample with a recently published UPLC configuration which has enabled the separation of a wide range of compounds, including amino acids ${ }^{26}$. This chromatographic setup was combined with a Triple Quadrupole mass spectrometer working in the targeted MRM mode. Meteorite water extract was aliquoted and dried. One aliquot was then placed in phosphate buffer at $30^{\circ} \mathrm{C}$. Amino acids composition was recorded straightaway and after $4 \mathrm{~h}$ of incubation with or without $\mathrm{APM}$ (Murchison $\mathrm{t}=0 \mathrm{~h}, \mathrm{t}=4 \mathrm{~h}$ and $\mathrm{t}=4 \mathrm{~h}$ APM respectively, Figure 2, Table S3). In parallel, another aliquot was submitted to $6 \mathrm{M} \mathrm{HCl}$ hydrolysis for $24 \mathrm{~h}$ (Murchison $\mathrm{HCl}$ hydrolysis, Figure 2).

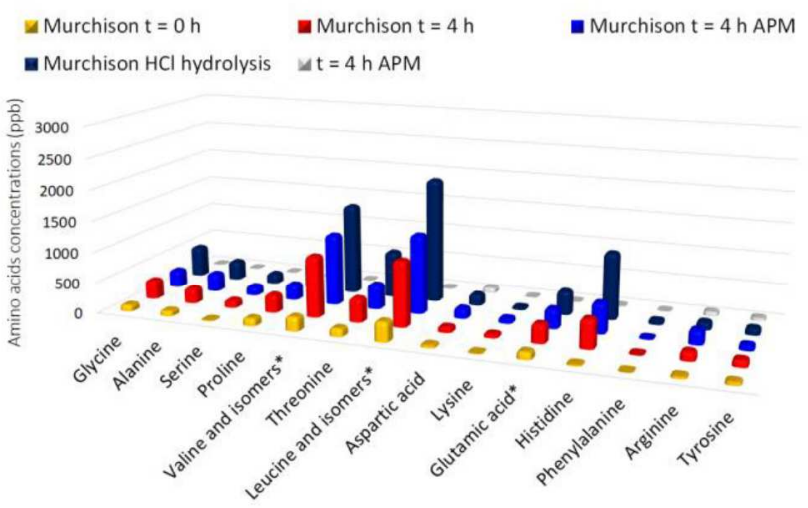

Figure 2. Evolution of the signals of amino acids in Murchison water extracts. The internal standard, i.e. trimethionine was added to the sample just before UPLC-MRM MS analysis. The star fitted to amino acid's names meant that their area was divided by 5 just to be shown on the same scale as the other amino acids. 
In these experiments, fourteen proteogenic amino acids and isomers were detected with confidence in the meteorite's samples in the same ppb concentrations as reported previously ${ }^{11,27-}$ ${ }^{31}$. Whereas proline, histidine and arginine have already been identified in Murchison after $\mathrm{HCl}$ hydrolysis ${ }^{23}$, they have been rarely found free in meteorites. Furthermore, in contrast to earlier studies, we noted a rather low amount of glycine and alanine compared to the other amino acids. Such results could be attributed to variability across meteorite samples, the absence of chemical derivatisation in our analytical protocol compared to those described in the literature ${ }^{32}$, and the use of liquid chromatography and electrospray ionisation that could have enhanced the matrix effect of non-derivatised molecules present in complex heterogenous mixtures ${ }^{33,34}$. However, with such a non-common relative distribution of amino acids as well as the detection of histidine ${ }^{35}$, we could have not excluded a terrestrial contamination of the Murchison extract. On the other hand, since the main objective of our study was to demonstrate the suitability of the proteomics-based strategy for peptide bonds detection, a potential contamination appeared not problematic for pursuing our investigations.

We then assessed the amino acids signals in samples incubated in the absence of APM, in the presence of APM and in the presence of $\mathrm{HCl}$ (Figure 2). We noticed that after $4 \mathrm{~h}$ in the buffer, the signals of all amino acids increased significantly with different rates (Murchison $\mathrm{t}=0 \mathrm{~h} v s$ Murchison $\mathrm{t}=4 \mathrm{~h}$, Figure 2). This indicated the presence of amino acids precursors with water-sensitive chemical bonds in the meteorite extract. We next measured the amount of amino acids after $4 \mathrm{~h}$ of incubation with APM. To avoid misinterpretation, we also verified that the increase in amino acids observed with the enzyme was not due to APM auto-hydrolysis ( $\mathrm{t}=4 \mathrm{~h}$ APM, Figure 2). In comparison to the experiments conducted without the enzyme, the quantities of alanine, serine, valine and isomers, threonine, leucine and isomers, aspartic acid, lysine, histidine, phenylalanine and arginine found in Murchison were 1.1 to 1.9 -fold higher (Murchison $\mathrm{t}=4 \mathrm{~h} v$ s Murchison $\mathrm{t}=4 \mathrm{~h}$ APM in Figure 2 ). As expected, the exopeptidase had a moderate effect compared to the $\mathrm{HCl}$ conditions which generated a significant increase of amino acid's concentrations (except arginine and lysine) (Murchison $\mathrm{t}=4 \mathrm{~h}$ APM vs Murchison $\mathrm{HCl}$ hydrolysis in Figure 2). Thus, this assay showed that, except for arginine which was released through APM auto-digestion, the rise in amino acids signals in the presence of APM was the consequence of the enzyme-catalyzed cleavage of peptide bonds. In comparison, in the acidic hydrolyzed meteorite extract, all amino acids precursors, either peptidic or not, were unselectively hydrolyzed.

To get a proof of presence of peptide sequences in the Murchison extract, we then exploited the stereoselectivity of APM. Indeed, although the enzyme exhibits a broad affinity towards most amino acid residues (except proline which resists to hydrolysis) ${ }^{12,20}$, its kinetics of peptide bonds hydrolysis is greatly affected by the absolute configuration of the two $N$-terminal residues (Figure S5a). Indeed, we showed that APM preferentially cleaved peptide bonds between two consecutive L-amino acids without any racemization (Figure S6) ${ }^{14-16,36}$. Therefore, the treatment of meteoritic extract with APM should significantly enhance the concentrations of L-amino acids if peptide bonds are present in the sample while the amounts of D-enantiomers should only slightly vary.
To test this hypothesis, we developed a chiral UPLC-MRM MS method based on the work of Konya and colleagues ${ }^{37}$ to enable the enantiomeric separation of amino acids in a very short time analysis (except proline and histidine) (Figure S8. Thereafter, we confirmed the stereoselectivity of APM for the hydrolysis of L-homochiral peptide bonds with three of the trialanine stereoisomers (L-Ala-L-Ala-L-Ala, D-Ala-D-Ala-D-Ala and L-Ala-D-Ala-L-Ala) used as model peptides. In these experiments, the L-homochiral tri-alanine was indeed totally digested by the exopeptidase within $4 \mathrm{~h}$ while the two other isomers were only partially consumed (Figure S5b). Similar results were obtained when L- and D-homochiral penta-alanine were incubated together in isomolar concentration with APM. These outcomes confirmed that APM hydrolyses faster $N$-terminal L-homochiral peptide bonds.

Once we have verified that the meteorite's extraction conditions $\left(100^{\circ} \mathrm{C}\right.$ for $\left.20 \mathrm{~h}\right)$ did not generate neither peptide cleavage nor racemization (Figure S7), the Murchison extract was incubated with or without APM in phosphate buffer for $4 \mathrm{~h}$ and the amount of L- and D-amino acids was investigated in each case using our chiral analytical method. The L- and/or D-enantiomers of alanine, serine, valine, threonine, leucine, aspartic acid, glutamic acid, phenylalanine, arginine, lysine, proline and histidine were detected in the sample (Figure S8). Isoleucine, alloisoleucine, and the non-biogenic isovaline were also detected.

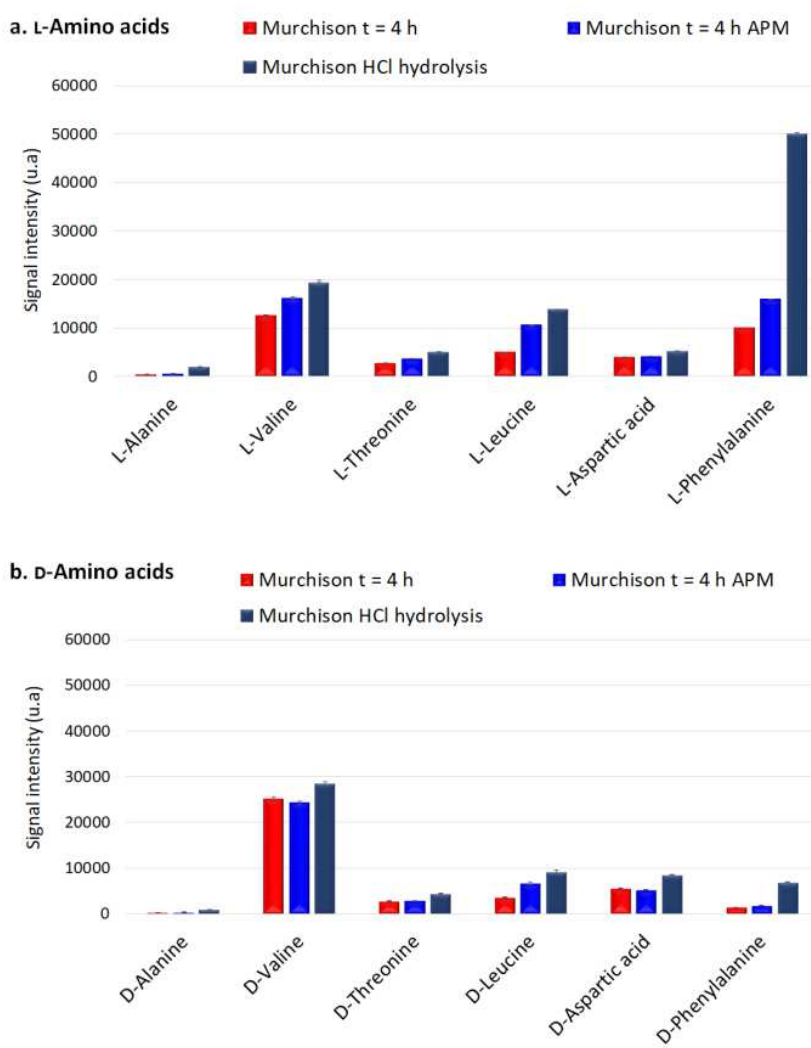

Figure 3. Monitoring of amino acid MS signals after $\mathrm{HCl}$ and APM hydrolysis. Signals of L-amino acids (a) and D-amino acids (b) in Murchison in the absence of APM (Murchison $t=4 \mathrm{~h}$ ), in the presence of APM (Murchison t $=4 \mathrm{~h} \mathrm{APM}$ ), and after $\mathrm{HCl}$ hydrolysis (Murchison $\mathrm{HCl}$ hydrolysis) (data from deconvoluted peaks, Figure S4). Note that MS signals were not proportional to amino acids 
concentrations since it depended on amino acids MS response coefficients. For each amino acid enantiomer, error bar was obtained by multiplying its signal value by its variation coefficient calculated from the injection of the 48/52, 50/50, 52/48 standard solutions.

We next focused our attention on the amino acids for which both enantiomers presented resolved chromatographic peaks (alanine, valine, threonine, leucine, aspartic acid and phenylalanine in Figure S8). Their MS signals obtained under each condition (without APM, with APM or $\mathrm{HCl}$ ) were deconvoluted (Figure S8). MS signals values were extracted and presented in Figure 3.

For these six amino acids, the signals of both enantiomers increased significantly when Murchison extract was submitted to $\mathrm{HCl}$ hydrolysis in comparison to the non-treated sample (2.9fold and 4.2-fold for D- and L-alanine, 1.1-fold and 1.6-fold for D- and L-valine, 1.6-fold and 1.8-fold for D- and L-threonine, 2.5-fold and 2.8-fold for D- and L-leucine, 1.5-fold and 1.3-fold for D- and L-aspartic acid, and 4.8-fold and 5.1-fold for D- and L-phenylalanine; Murchison t $=4 \mathrm{~h} v s$ Murchison $\mathrm{HCl}$ hydrolysis). These data demonstrated that both $\mathrm{D}$ - and L-amino acids were indeed present in the form of precursors, peptidic or not. On the other hand, the enzyme generated a rise of the amount of all L-enantiomers (1.4-fold for L-alanine, 1.3-fold for L-valine, 1.3-fold for L-threonine, 2.1-fold for L-leucine, 1.03-fold for L-aspartic acid, and 1.6-fold for L-phenylalanine; Murchison $\mathrm{t}=4 \mathrm{~h}$ vs Murchison $\mathrm{t}=4 \mathrm{~h}$ APM). Hence, our results revealed that these six amino acids were involved in peptide bonds present in the meteorite extract prior to their APM-catalyzed hydrolysis. The MS signals of D-alanine, D-valine, D-threonine, and D-aspartic acid were similar with or without APM. On the other hand, increases of D-leucine (1.8-fold) and D-phenylalanine (1.3-fold) amounts were observed in the sample treated with the exopeptidase. While such increases were lower than those recorded for their corresponding L-enantiomers, these two D-amino acids must have been included in peptide sequences since their releases were catalyzed by APM. This result constitutes the first indirect proof of presence of extra-terrestrial peptide bonds involving non-proteogenic D-amino acids in the Murchison meteorite.

These sets of experiments clearly demonstrated the interest of this proteomics-based strategy for indicating L- and D-amino acids specifically involved in peptide sequences within a meteorite extract. Thus, it opens a new pathway to explore molecules included in minor bodies, for instance through the investigation of other enzymatic systems. Combined with isotope analysis, this chemo-bio analysis could enable the search for extraterrestrial peptides in objects of the Solar System. Applied on peptides containing non terrestrial $\alpha$-amino acids (e.g. isovaline) or with other peptidases, this strategy will then help in deepening the knowledge on the organic matter that may have seeded the early Earth and later triggered the emergence of life.

\section{ASSOCIATED CONTENT}

\section{Supporting Information}

The Supporting Information is available free of charge on the ACS Publications website.
It presents a description of the materials and methods used for the proof of concept on standard solutions, for the preparation and UPLC-MRM MS analysis of Murchison hydrolyzed samples and for investigating peptide bonds in Murchison water extract.

\section{AUTHOR INFORMATION}

\section{Corresponding Author}

* Pauline Poinot - UMR CNRS 7285, Institut de Chimie des Milieux et Matériaux de Poitiers (IC2MP), E.BiCoM Team, 4 rue Michel-Brunet, TSA 51106, 86073 Poitiers cedex 9, France.

email: pauline.poinot@univ-poitiers.fr

\section{Author Contributions}

P.P. get the idea to transpose a proteomics strategy for peptides detection in extraterrestrial samples and designed the enzymatic workflow. P.P., C.G.R. and N.K.V.L. supervised the development of the whole analytical methods. P.P. and S.P. get the idea to exploit the $\mathrm{L} / \mathrm{D}$ ratio of amino acids to confirm unambiguously the presence of peptides in the meteorites. C.G.R. performed meteorite's extraction and $\mathrm{HCl}$ hydrolysis. J.L., F.D. and Q.B.R. performed analytical experiments. All enzymatic digestions were conducted by B.E. HCl hydrolysis of standard compounds was carried out by F.D.. J.L., B.E. and A.R. collected all the data and reconstructed the figures. J.L., C.G.R., F.D., L.S.H and P.P. wrote the methods section. P.P., G.D., S.P. and L.S.H wrote the paper with input from all other authors.

\section{Notes}

The authors declare no competing financial interest.

\section{ACKNOWLEDGMENT}

This research was carried out within exobiology technology programs with the financial support of the French National Space Agency (CNES, R-S18/SU-0003-072). We gratefully acknowledge Frederic Courtade for his implication in this project. The authors acknowledge financial support from the European Union (ERDF) and "Région Nouvelle Aquitaine". G.D. and A.R. also thanks the French National Research Agency for its funding (RAHIIA_SSOM ANR-16-CE29-0015).

\section{REFERENCES}

(1) Chyba, C.; Thomas, P.; Brookshaw, L.; Sagan, C. Cometary Delivery of Organic Molecules to the Early Earth. Science 1990, 249 (4967), 366. https://doi.org/10.1126/science. 11538074.

(2) Simoneit, B. R. T.; Summons, R. E.; Jahnke, L. L. Biomarkers as Tracers for Life on Early Earth and Mars. Orig. Life Evol. Biosph. 1998, 28 (4), 475-483. https://doi.org/10.1023/A:1006508012904.

(3) Irvine, W. M. Extraterrestrial Organic Matter: A Review. Orig. Life Evol. Biosph. 1998, 28 (4), 365-383. https://doi.org/10.1023/A:1006574110907.

(4) Altwegg, K.; Balsiger, H.; Bar-Nun, A.; Berthelier, J.-J.; Bieler, A.; Bochsler, P.; Briois, C.; Calmonte, U.; Combi, M. R.; Cottin, H.; De Keyser, J.; Dhooghe, F.; Fiethe, B.; Fuselier, S. A.; Gasc, S.; Gombosi, T. I.; Hansen, K. C.; Haessig, M.; Jäckel, A.; Kopp, E.; Korth, A.; Le Roy, L.; Mall, U.; Marty, B.; Mousis, O.; Owen, T.; Rème, H.; Rubin, M.; Sémon, T.; Tzou, C.-Y.; Hunter Waite, J.; Wurz, P. Prebiotic Chemicals-Amino Acid and Phosphorus-in the Coma of 
Comet 67P/Churyumov-Gerasimenko. Sci. Adv. 2016, 2 (5), e1600285. https://doi.org/10.1126/sciadv.1600285.

Botta, O.; Bada, J. L. Extraterrestrial Organic Compounds in Meteorites. Surv. Geophys. 2002, 23 (5), 411-467. https://doi.org/10.1023/A:1020139302770.

(6)

Callahan, M. P.; Smith, K. E.; Cleaves, H. J.; Ruzicka, J.; Stern, J. C.; Glavin, D. P.; House, C. H.; Dworkin, J. P. Carbonaceous Meteorites Contain a Wide Range of Extraterrestrial Nucleobases. Proc. Natl. Acad. Sci. 2011, 108 (34), 13995. https://doi.org/10.1073/pnas.1106493108.

(7) Pizzarello, S.; Cooper, G. W.; Flynn, G. J. The Nature and Distribution of the Organic Material in Carbonaceous Chondrites and Interplanetary Dust Particles. Meteorites and the Early Solar System II. 2006, pp 625-651.

(8) Sephton, M. A. Organic Compounds in Carbonaceous Meteorites. Nat. Prod. Rep. 2002, 19 (3), 292-311. https://doi.org/10.1039/B103775G.

(9) Kvenvolden, K.; Lawless, J.; Pering, K.; Peterson, E.; Flores, J.; Ponnamperuma, C.; Kaplan, I. R.; Moore, C. Evidence for Extraterrestrial Amino-Acids and Hydrocarbons in the Murchison Meteorite. Nature 1970, 228 (5275), 923-926. https://doi.org/10.1038/228923a0.

(10) Koga, T.; Naraoka, H. A New Family of Extraterrestrial Amino Acids in the Murchison Meteorite. Sci. Rep. 2017, 7 (1), 636. https://doi.org/10.1038/s41598-017-00693-9.

(11) Glavin, D. P.; Dworkin, J. P.; Aubrey, A.; Botta, O.; Doty, J. H.; Martins, Z.; Bada, J. L. Amino Acid Analyses of Antarctic CM2 Meteorites Using Liquid Chromatography-Time of Flight-Mass Spectrometry. Meteorit. Planet. Sci. 2010, 41 (6), 889-902.

https://doi.org/10.1111/j.1945-

5100.2006.tb00493.x.

(12) Wachsmuth, E. D.; Fritze, I.; Pfleiderer, G. An Aminopeptidase Occurring in Pig Kidney. II. A Study on the Mechanism of the Hydrolysis. Biochemistry 1966, 5 (1), 175-182. https://doi.org/10.1021/bi00865a023.

(13) Doucette, A.; Li, L. Investigation of the Applicability of a Sequential Digestion Protocol Using Trypsin and Leucine Aminopeptidase $\mathrm{M}$ for Protein Identification by Matrix-Assisted Laser Desorption/Ionization - Time of Flight Mass Spectrometry. Proteomics 2001, 1 (8), 987-1000. https://doi.org/10.1002/1615-9861(200108)1:8<987::AIDPROT987>3.0.CO;2-5.

(14) Sánchez-Hernández, L.; Serra, N. S.; Marina, M. L.; Crego, A. L. Enantiomeric Separation of Free L- and d-Amino Acids in Hydrolyzed Protein Fertilizers by Capillary Electrophoresis Tandem Mass Spectrometry. J. Agric. Food Chem. 2013, 61 (21), 5022-5030. https://doi.org/10.1021/jf4013345.

(15) Ewing, M. A.; Wang, J.; Sheeley, S. A.; Sweedler, J. V. Detecting D-Amino Acid-Containing Neuropeptides Using Selective Enzymatic Digestion. Anal. Chem. 2008, 80 (8), 28742880. https://doi.org/10.1021/ac7025173.

(16) Livnat, I.; Tai, H.-C.; Jansson, E. T.; Bai, L.; Romanova, E. V.; Chen, T.; Yu, K.; Chen, S.; Zhang, Y.; Wang, Z.; Liu, D.; Weiss, K. R.; Jing, J.; Sweedler, J. V. A D-Amino Acid-Containing Neuropeptide Discovery Funnel. Anal. Chem. 2016, 88 (23), 11868-11876. https://doi.org/10.1021/acs.analchem.6b03658.

(17) Bai, L.; Sheeley, S.; Sweedler, J. V. Analysis of Endogenous D-Amino Acid-Containing Peptides in Metazoa. Bioanal. Rev. 2009, 1 (1), 7-24. https://doi.org/10.1007/s12566-0090001-2.

(18) Checco, J. W.; Zhang, G.; Yuan, W.; Le, Z.; Jing, J.; Sweedler, J. V. Aplysia Allatotropin-Related Peptide and Its Newly Identified d-Amino Acid-Containing Epimer Both Activate a Receptor and a Neuronal Target. J. Biol. Chem. 2018, $293 \quad$ (43), 16862-16873. https://doi.org/10.1074/jbc.RA118.004367.
(19) Mast, D. H.; Checco, J. W.; Sweedler, J. V. Differential PostTranslational Amino Acid Isomerization Found among Neuropeptides in Aplysia Californica. ACS Chem. Biol. 2020, 15 (1), 272-281. https://doi.org/10.1021/acschembio.9b00910.

(20) Janas, R. M.; Socha, J.; Janas, J.; Warnawin, K. Neutral Endopeptidase Activity Is Not Elevated in Serum in Children with Cholestatic Liver Disease: A Unique Role of Aminopeptidase-M in Sequential Hydrolysis of Peptides. Dig. Dis. Sci. 2002, $\quad 47 \quad$ (8), $\quad 1766-1774$ https://doi.org/10.1023/A:1016440511089.

(21) Shimoyama, A.; Ogasawara, R. Dipeptides and Diketopiperazines in the Yamato-791198 and Murchison Carbonaceous Chondrites. Orig. Life Evol. Biosph. 2002, 32 (2), 165-179. https://doi.org/10.1023/A:1016015319112.

(22) Cronin, J. R.; Pizzarello, S. Amino Acids in Meteorites. Adv Space Res. 1983, 3 (9), 5-18. https://doi.org/10.1016/02731177(83)90036-4.

(23) McGeoch, J. E. M.; McGeoch, M. W. Polymer Amide in the Allende and Murchison Meteorites. Meteorit. Planet. Sci. 2015, $50 \quad$ (12), https://doi.org/10.1111/maps.12558.

(24) Meierhenrich, U. J.; Muñoz Caro, G. M.; Bredehöft, J. H.; Jessberger, E. K.; Thiemann, W. H.-P. Identification of Diamino Acids in the Murchison Meteorite. Proc. Natl. Acad. Sci. $\begin{array}{llllll}S . & \text { A. 2004, } 101 & \text { (25), 9182-9186. }\end{array}$ https://doi.org/10.1073/pnas.0403043101.

(25) Cronin, J. R. Acid-Labile Amino Acid Precursors in the Murchison Meteorite. Orig. Life 1976, 7 (4), 343-348. https://doi.org/10.1007/BF00927929.

(26) Eddhif, B.; Allavena, A.; Liu, S.; Ribette, T.; Abou Mrad, N.; Chiavassa, T.; d'Hendecourt, L. L. S.; Sternberg, R.; Danger, G.; Geffroy-Rodier, C.; Poinot, P. Development of Liquid Chromatography High Resolution Mass Spectrometry Strategies for the Screening of Complex Organic Matter: Application to Astrophysical Simulated Materials. Talanta 2018, 179, 238-245. https://doi.org/10.1016/j.talanta.2017.11.008.

(27) Callahan, M. P.; Martin, M. G.; Burton, A. S.; Glavin, D. P.; Dworkin, J. P. Amino Acid Analysis in Micrograms of Meteorite Sample by Nanoliquid Chromatography-High-Resolution Mass Spectrometry. J. Chromatogr. A 2014, 1332, 30 34. https://doi.org/10.1016/j.chroma.2014.01.032.

(28) Engel, M. H.; Macko, S. A. Isotopic Evidence for Extraterrestrial Non- Racemic Amino Acids in the Murchison Meteorite. Nature 1997, 389, 265.

(29) Engel, M. H.; Nagy, B. Distribution and Enantiomeric Composition of Amino Acids in the Murchison Meteorite. Nature 1982, 296 (5860), 837-840. https://doi.org/10.1038/296837a0.

(30) Glavin, D. P.; Dworkin, J. P.; Aubrey, A.; Botta, O.; Doty III, J. H.; Martins, Z.; Bada, J. L. Amino Acid Analyses of Antarctic CM2 Meteorites Using Liquid Chromatography-Time of Flight-Mass Spectrometry. Meteorit. Planet. Sci. 2006, 41 (6), 889-902. https://doi.org/10.1111/j.19455100.2006.tb00493.x.

(31) Pizzarello, S.; Cronin, J. R. Non-Racemic Amino Acids in the Murray and Murchison Meteorites. Geochim. Cosmochim. Acta 2000, 64 (2), 329-338. https://doi.org/10.1016/S00167037(99)00280-X.

(32) Song, M.; Hang, T.-J.; Wang, C.; Yang, L.; Wen, A.-D. Precolumn Derivatization LC-MS/MS Method for the Determination and Pharmacokinetic Study of Glucosamine in Human Plasma and Urine. J. Pharm. Anal. 2012, 2 (1), 19-28. https://doi.org/10.1016/j.jpha.2011.08.003.

(33) Nebbioso, A.; Piccolo, A.; Spiteller, M. Limitations of Electrospray Ionization in the Analysis of a Heterogeneous Mixture of Naturally Occurring Hydrophilic and Hydrophobic Compounds. Rapid Commun. Mass Spectrom. 2010, 24 (21), 3163-3170. https://doi.org/10.1002/rcm.4749. 
(34) Antignac, J.-P.; de Wasch, K.; Monteau, F.; De Brabander, H.; Andre, F.; Le Bizec, B. The Ion Suppression Phenomenon in Liquid Chromatography-Mass Spectrometry and Its Consequences in the Field of Residue Analysis. EURORESIDUE V Noordwijkerhout Neth. 10-12 May 2004 2005, 529 (1), 129-136. https://doi.org/10.1016/j.aca.2004.08.055.

(35) Vázquez-Salazar, A.; Becerra, A.; Lazcano, A. Evolutionary Convergence in the Biosyntheses of the Imidazole Moieties of Histidine and Purines. PLOS ONE 2018, 13 (4), e0196349. https://doi.org/10.1371/journal.pone.0196349.

(36) Velmurugan, P.; Jonnalagadda, R. R.; Unni Nair, B. Engineering D-Amino Acid Containing Collagen Like Peptide at the
Cleavage Site of Clostridium Histolyticum Collagenase for Its Inhibition. Plos One 2015, $10 \quad$ (5), e0124398. https://doi.org/10.1371/journal.pone.0124398.

(37) Konya, Y.; Taniguchi, M.; Furuno, M.; Nakano, Y.; Tanaka, N.; Fukusaki, E. Mechanistic Study on the High-Selectivity Enantioseparation of Amino Acids Using a Chiral Crown Ether-Bonded Stationary Phase and Acidic, Highly Organic Mobile Phase by Liquid Chromatography/Time-of-Flight Mass Spectrometry. J. Chromatogr. A 2018, 1578, 35-44. https://doi.org/10.1016/j.chroma.2018.10.004. 